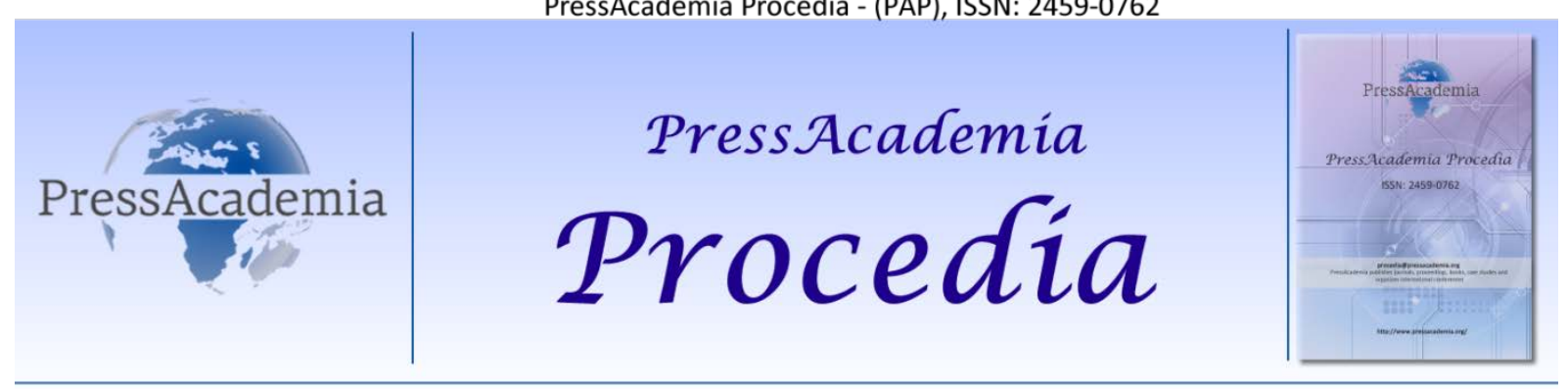

Global Business Research Congress (GBRC), May 26-27, 2016, Istanbul, Turkey.

\title{
PMI METHODOLOGY IN PROJECT MANAGEMENT AND APPLICABILITY IN TURKEY
}

\section{DOI: 10.17261/Pressacademia.2016118678}

\section{Huseyin Mert, Nurdan Kucukkoglu}

${ }^{1}$ Okan Üniversitesi, huseyin.mert@okan.edu.tr

${ }^{2}$ Okan Üniversitesi, nurdankucukoglu@gmail.com

\begin{abstract}
Project Management is a business management issues with specific qualifications. Scientific studies of this issue for better understanding of the problems that may arise in order to make more effective solutions has increased considerably in recent years. Increasing the project scales and related resources contributes the need of effectiveness in this area gradually increase. Probability of project success will rise through the development of reliable rules and efficient management system requirements as a result of the theoretical and practical studies by implemented project managers.PMI (Project Management Institute) methodology is the subject of this research is being used widely today all over the world. The study that we made investigates innovations which brings this methodology and applicability at telecommunication companies in our country.
\end{abstract}

Keywords: Project, project management, succes project

JEL Codes: L20, L21, O21, O22

\section{PROJE YÖNETIMINDE PMI METODOLOJISI VE TÜRKIYE'DE UYGULANABILIRLIĞi}

\section{ÖZET}

Proje Yönetimi, kendine özgü nitelikler taşıyan bir iş yönetimi konusudur. Bu konunun daha iyi kavranması ve ortaya çıkabilecek sorunların daha etkin çözümlere ulaştırılabilmesi için yapılan bilimsel çalışmalar son yıllarda oldukça artmıştır. Proje ölçeklerinin ve buna bağlı olarak kullanılan kaynakların artması, bu alanda etkinliğin sağlanması konusuna duyulan ihtiyacın giderek artmasına sebep olmaktadır. Bu ihtiyacın sonucu olarak yapılan kuramsal ve uygulamalı çalışmalar ile proje yöneticilerinin uygulayabilecekleri güvenilir kurallar ve etkin yönetim sistemlerinin geliştirilmesi sayesinde projelerin başarı ihtimalleri de yükselecektir. Çalışmamıza konu olan PMI (Project Management Institute) metodolojisi günümüzde tüm dünyada yaygın olarak kullanılmaktadır. Yapmış olduğumuz bu çalışma ile yöntemin getirdiği yenilikler ve özellikle Telekomünikasyon firmalarında yaygın olarak kullanılması sebebiyle, bu firmalar baz alınarak ülkemizde uygulanabilirliği incelenmiştir.

Anahtar Kelimeler: Proje, proje yönetimi, proje başarısı

JEL Kodları: L20, L21, O21, O22

\section{GiRiş}

1860 yılında Amerika'da uluslararası taşımacılığın başlamasıyla birlikte, büyük ölçekli projeler gündeme gelmiştir. Bu durum karşısında alınan önemli kararlar ve geliştirilen yöntemler, proje yönetiminin temellerini oluşturmuştur. Proje Yönetiminin yöntemsel olarak geliştirilmesinde öncülerden olan Frederick Taylor (18561915); uzun ve zorlu çalışmalar yerine işgücü çalışmalarının bilimsel olarak analiz edilmesi sayesinde, verimliliğin ve kapsamın geliştirilip veya değiştirilmesinin çok daha verimli olacağı fikrini ortaya koymuştur. 
Frederick Taylor ile yakın dönem yönetim danışmanlarından olan Henry Gantt (1861-1919); operasyonların detaylandırılması yöntemini geliştirmiştir. Gantt şeması olarak adlandırılan bu yöntem ile projenin zaman çizelgesini her bir aşamaya ait aktiviteleri ve iş kırılım yapılarını oluşturarak, en iyi açıklayan yöntem olma özelliğini günümüze kadar korumaktadır.

Proje Yönetimi açıklanırken PMı (Project Management İnstitute) metodolojisinin seçilme amacı kullanımının yaygın olmasından kaynaklanmaktadır. Yöntem bu açıdan incelenmeye değer bulunmuştur. Çalışmada yöntemin temel kaynağı olan Proje Yönetimi Bilgi Birikimi Kaynağı olan PMBOK'ın 5. Baskısı temel kaynak kabul edilmiştir. Çalışma söz konusu kaynağın kavramları kullanılarak açıklanmıştır. Yöntem açıklaması yapılırken literatür taraması ve derinlemesine mülakat yöntemi kullanılmıştır. Bu sayede sektörde çalışan bir proje yöneticisinden yöntemin uygulamalarına ilişkin görüşleri alınmıştır.

Proje yönetimi yaygın olarak bilişim sektöründe kullanılmakta olması sebebiyle, bu sektöre yönelik çok sayıda yöntem ve uygulama geliştirilmiştir. Hazırlanmış olan bu çalışma, proje yönetiminin tüm sektörlerde yaygın kullanım şekli üzerinde durdurduğundan bilişim sektörüne yönelik bu yöntemlere yer verilmemiştir. Proje yönetimi denilince akla gelen, sayısal yöntemlerden de bahsedilmiş fakat yöntemin temel hedefi üzerinde durulduğundan, söz konusu yöntemler ayrıntısıyla ele alınmamıştır.

Çalışmanın sonucunda Proje Yönetim metodolojisinin genel uygulama esas ve yöntemlerinin ortaya konulması ve Türkiye'de uygulanması tartışılması hedeflenmiştir.

3 bölümden oluşan çalışma; Proje Yönetimi ve Organizasyon Modelleri, Türkiye' de PMI methodolojisinin kullanımı ve Sonuç bölümünü içermektedir.

\section{PROJE YÖNETIMI KAVRAMI VE ORGANIZASYON MODELLERI}

Proje yönetimi, proje hedeflerini gerçekleştirmek üzere kaynakların yönlendirilmesi ve kullanılmasıdır. Bununla birlikte, bu tanım Proje Yönetiminin proje açısından kritik olguları üzerine düşünmeye sevk etmesi açısından yeterli olmamaktadır.

Proje Yönetimi, sistematik süreçlerin takip ettiği hem bilimsel hem sosyal bir olguyu ifade etmektedir. PMI proje yönetimini bilgi alanlarına ve süreç gruplarına ayırmıştır.

Süreç gruplarında yüksek önem dereceli gruplar birbirini izlemektedir. Bunlar; başlangıç, planlama, yürütme, kontrol ve denetim ve kapanış süreçleridir.

Bilgi alanları ise; entegrasyon, kapsam, zaman, maliyet, kalite, insan kaynakları, iletişim, risk ve tedarik yönetimi ve paydaş yönetimidir. ${ }^{1}$

Uzun süreli karmaşık projeler, genellikle birbirine paralel iş gruplarında çalışan çok sayıda ekip tarafından üretilir. Eğer yöneticiler aradaki boşluklarda oluşacak her gelişmeyi önceden tahmin etmeyi başaramazlarsa, bu iş grupları başarılı şekilde birleşemeyecektir.

\subsection{Proje Organizasyonu Kavramları}

Proje Yönetim Ofisi: Projelerin merkezi olarak, yönetimle bağlantılı çeşitli sorumluluklar üstlenen, organizasyonel birimi ifade etmektedir.

Proje Paydaşları: Projeye dahil olan kişi ve kurumları ifade ettiği gibi, proje tamamlandığında sonuçtan olumlu ya da olumsuz etkilenecek herkesi kapsamaktadır.

Proje Sponsoru: Projeyi başlatan ve proje için gerekli kaynakları tedarik eden kişiyi ifade etmektedir.

Proje Yöneticisi: Proje Yöneticisi, projenin, kapsam, zaman, bütçe ve kalite kısıtları dahilinde başarısından sorumlu kişidir.

Proje yöneticisinin başarılı olabilmesi için aşağıdaki asgari özellikleri taşıması beklenir ${ }^{2}$

\footnotetext{
${ }^{1}$ Andrew R. Barron, Merrie Barron, History of Project Management, cnx.org/content/m31428/latest (03.04.2015)
} 
- $\quad$ Organizasyon ve liderlik tecrübesi

- Gerekli kaynaklara başvurma

- Değişik kaynakları koordine edebilme becerisi

- $\quad$ Iletişim ve çeşitli yöntemleri uygulama yeteneği

- Elemanlara sorumluluk verme ve onları izleme becerisi

- Güvenilirlik

Fonksiyon Yöneticisi: Projenin ihtiyacı olan kaynakları planlanması, atamaların gerçekleştirilmesi ve iş dağılımı fonksiyon yöneticisi tarafından gerçekleştirilir. İşlerin prosedür ve talimatlara uyumlu ilerlemesini sağlar.

Ekip Lideri: Projenin detay planını oluşturarak takibini yapma görevini üstlendiği gibi, açık uçlu konuları, riskleri, süreçler arasındaki ilişkileri Proje yöneticisi ve Fonksiyon yöneticisine aktarır.

Ekip Üyesi: Kurum içindeki süreçleri, kuralları uygular ve gelişime katkıda bulunurken, ekip lideri ve fonksiyon yöneticisini düzenli olarak bilgilendirir.

\subsection{Proje Organizasyonu}

Projenin gerçekleştirilmesinden sorumlu kişilerin, proje içindeki hiyerarşisinin belirlendiği yapılardır.

Tanımlanmış 4 çeşit organizasyon yapısı bulunmaktadır:

- Fonksiyonel Organizasyon

- Matris Organizasyon

- Proje Bazlı Organizasyon

- Karma Organizasyon

\subsubsection{Fonksiyonel Organizasyon}

Klasik fonksiyonel organizasyon yapısı, her çalışanın üstünün açıkça tanımlanmış olduğu bir olduğu hiyerarşi modelidir. Çalışanlar en üst düzeyde, üretim, pazarlama, mühendislik ve muhasebe gibi uzmanlıklara göre gruplanmıştır. Uzmanlıklar, makine mühendisliği ve elektrik mühendisliği gibi daha odaklı fonksiyonel alt birimlere ayrılabilir. Fonksiyonel organizasyon modelinde, her bölüm proje işlerini diğer bölümlerden bağımsız olarak yürütmektedir.

\subsubsection{Matris Organizasyon Yapısı}

Fonksiyonel organizasyon ve proje bazlı organizasyon özelliklerinin karışımından oluşmaktadır. Matris organizasyonlar, fonksiyon yöneticileri ve proje yöneticileri arasındaki göreli güç ve etki düzeyine bağlı olarak, zayıf, dengeli ve güçlü olarak sınıflanabilmektedir.

\subsubsection{Proje Bazlı Organizasyon Yapısı}

Bir ucunda fonksiyonel organizasyonun bulunduğu spektrumun diğer ucunda da proje bazlı organizasyon yer alır. Proje bazlı organizasyonda, ekip üyeleri çoğu zaman birlikte konumlandırımıştır. Organizasyonun kaynaklarının büyük bir kısmı proje çalışmasına dahil edilmiştir ve proje yöneticileri önemli derecede bağımsızlığa ve yetkiye sahiptirler.

\subsubsection{Karma Organizasyon Yapısı}

Karma organizasyon yapısı,büyük ölçüde tüm yapıları, çeşitli düzeylerde içeren organizasyon yapılarını ifade etmektedir. Örneğin, temel olarak fonksiyonel olan bir organizasyon ile kritik bir projeyi yürütmek için özel bir

\footnotetext{
${ }^{2}$ (Thomsett, 2006)
} 
proje ekibi kurabilir. Böyle bir ekip proje bazlı bir organizasyondaki proje ekibinin pek çok özelliğini taşıyabilir. Ekip farklı fonksiyonel bölümlerde görev yapan tam zamanlı çalışanlardan oluşabilir, kendi prosedürleri kümesi oluşturabilir ve hatta proje süresince standart ve resmi raporlama yapısının dışında faaliyet gösterebilir. Ayrıca, bir organizasyonda, projelerinin çoğunu güçlü matris ile yürütülürken, bazı küçük projelerinin fonksiyonel departmanlar tarafından yürütülmesine müsaade edilebilir.

\section{3. Proje Süreçleri}

Başlangıç Süreç Grubu: Proje Başlatma Belgesinin geliştirilmesi ve yayınlanması; Paydaşların Belirlenmesi ve Analizi bu aşamada gerçekleştirilen faaliyetleri içeren süreç grubunu ifade etmektedir.

Planlama Süreç Grubu : Projenin süresini ve maliyetinin belirlendiği ve yapılacak işlerin yol haritası, alternatif yaklaşımların belirlenmesinin sağlandığı süreç grubunu ifade etmektedir.

Yürütme Süreç Grubu: Kalite güvencesinin sağlanması, proje ekibinin yönetilmesi, tedariklerin yürütülmesi, paydaş katılımının yönetilmesi faaliyetlerini içeren süreç grubunu ifade etmektedir.

Proje İzleme ve Kontrol Süreç Grubu: Kapsam kontrolü, zaman çizelgesinin kontrolü, maliyetlerin kontrolü, kalitenin kontrolü faaliyetlerini içeren süreç grubunu ifade etmektedir.

Projenin Kapanış Süreç Grubu: Projenin kapanış işlemleri, proje sonucunun değerlendirilmesi süreçlerini ifade etmektedir.

\section{4. Proje Yönetim Bileşenleri}

Proje Entegrasyon Yönetimi - Proje Entegrasyon Yönetimi, Proje Yönetimi Süreç Grupları içindeki çeşitli süreçleri ve proje yönetimi aktivitelerini belirleyen, tanımlayan, birleştiren ve koordine eden süreçleri ve aktiviteleri içerir. Proje yönetimi bağlamında entegrasyon, projenin paydaş beklentilerini başarıyla yönetmek ve gereksinimleri bütünleştirme eylemlerini içine alır. Proje Entegrasyon Yönetimi, kaynakların tahsisi konusunda seçimler yapmayı, birbiriyle çelişen hedefler ve alternatifler arasında uzlaşma sağlamayı ve proje yönetimi Bilgi Alanları arasındaki karşılıklı bağımlılıkları yönetmeyi içerir. Proje yönetimi süreçleri genellikle iyi tanımlanmış ara yüzleri olan ayrı süreçler olarak sunulur, ama uygulamada bu süreçler iç içe geçer ve etkileşirler.

Proje Kapsam Yönetimi - Kapsam Yönetimi projenin tamamlanması için gerekli olan bütün iş paketlerinin tanımlanması aşamasıdır. Bu aşama kolay bir süreç gibi görünse de, anlaşmaya göre günlük yapılması gereken işler konusunda proje yöneticisinin atladığı konular olabilir. Pek çok kişi bunun farkında bile değildir. Böyle bir durumun önüne geçmek için yapılması izlenmesi gereken süreçler sırasıyla açıklanmıştır.

Kapsam Yönetiminin Planlanması; kapsamın nasıl tanımlanacağını, geliştirileceğini, izleneceğini, kontrol edileceğini ve doğrulanacağını açıklayan proje ya da program yönetimi planının bir parçasıdır. Kapsam yönetimin geliştirilmesi ve proje kapsamının ayrıntılandırılması, proje başlatma belgesinde bulunan bilgilerin analizi, varlıklarında bulunan tarihsel bilgiler ve diğer ilgili çevresel işletme faktörlerinin analizi yapılarak başlar. Bu plan ile proje kapsamı kaymasına ilişkin riskler azalır. ${ }^{3}$

Gereksinimlerin Toplanması; proje hedeflerine ulaşmak amacıyla, paydaşların ihtiyaçlarının ve gereksinimlerinin tanımlanması ve belgelenmesi sürecidir. Bu sürecin ana faydası, ürün kapsamı da dahil edilerek proje kapsamının tanımlanması projenin yönetilmesinin temelini oluşturmasıdır.

Kapsamın Tanımlanması; proje ve ürününün ayrıntılı bir tanımının oluşturulması sürecidir. Bu sürecin ana faydası, toplanan gereksinimlerden hangilerinin proje kapsamına dahil edileceği ve proje kapsamının dışında bırakılacağı tanımlanarak proje, hizmet veya sonuç sınırlarının tanımlanmasıdır.

İş Kırılım Yapısının (IKY) Oluşturulması; proje teslimatlarının ve proje çalışmalarının daha küçük ve yönetilebilir bileşenlere ayrılması sürecidir. Bu sürecin ana faydası teslimatların ne olacağına dair yapısal bir vizyon sağlamasıdır. ${ }^{4}$

\footnotetext{
${ }^{3}$ (Proje Yönetimi Bilgi Birikimi Kılavuzu )(PMBOK), s:108

${ }^{4}$ Proje Yönetimi Bilgi Birikimi Kılavuzu (PMBOK), s:125
} 
Kapsamın Onaylanması; tamamlanan proje teslimatlarının kabulünü resmileştirme sürecidir. Sürecin ana faydası kabul sürecine objektiflik getirmesi ve her teslimatı doğrulayarak nihai ürün, hizmet ya da sonuç kabulü şansını artırmasıdır.

Proje Zaman Yönetimi - Proje zaman yönetimi süreçleri ve bunlarla bağlantılı araçlar ve teknikler zaman çizelgesi yönetimi planında belgelenir. Zaman çizelgesi yönetim planı, Proje Yönetimi Planının Geliştirilmesi süreci aracılığıyla proje yönetim planı ile entegredir ve proje yönetimi planının altında yer alır. Zaman çizelgesi yönetimi planı, bir zaman çizelgeleme yöntemi ve zaman çizelgeleme aracını tanımlar. Bununla beraber hem formatı belirler hem de proje zaman çizelgesini geliştirmek ve kontrol etmek için kriter oluşturur. Seçilen zaman çizelgeleme yöntemi, zaman programlama aracında zaman çizelgesi modelini oluşturmak için kullanılan yapıyı ve algoritmaları tanımlar. ${ }^{5}$

Proje Maliyet Yönetimi - Proje Maliyet Yönetimi projenin onaylanan bütçe çerçevesinde tamamlanabilmesi için maliyetlerin planlanmasına, tahminine, bütçelenmesine, finanse edilmesine, fonlanmasına, yönetilmesine ve kontrolünün sağlanması süreçlerini içerir.

Proje Kalite Yönetimi - Proje Kalite Yönetiminin amacı projeye kalite fikrinin dahilinde bir ek değer katmasıdır. $\mathrm{Bu}$, kalite için bir plana sahip olmak, bu plan üzerinde kalite için gerekli düzenlemeleri yaparak çalışmaktır.

Proje İnsan Kaynakları Yönetimi - Proje ekibinin organize edilmesine, yönetilmesine ve yönlendirilmesine yönelik süreçleri içerir.

Proje İletişim Yönetimi- Proje bilgilerinin zamanında ve uygun şekilde üretilmesi toplanması, dağıtılması, saklanması, erişilmesi ve nihai olarak tanzim edilmesi için gerekli süreçleri içerir.

Proje Risk Yönetimi - Projede risk yönetiminin planlanması, belirlenmesi, analizi, yanıtlarının planlanması, izlenmesi ve kontrol edilmesi süreçlerini içerir.

Proje Tedarik Yönetimi - Gerekli ürünleri, hizmet ya da sonuçları proje ekibinin dışından satın almak ya da elde etmek için gereken süreçleri kapsar.

Proje Paydaş Yönetimi - Projeyi etkileyen veya projeden etkilenen kişilerin, grupların, veya şirketlerin belirlenmesi, onların beklentilerinin projeye olan etkilerinin analiz edilmesi sürecidir. Bu süreçte paydaşların beklentilerinin analiz edilmesi ve proje ile ilgili kararlar alınması konusunda görüşlerinin alınması sağlanır.

\subsection{Türkiye'de PMI Yönteminin Kullanımı}

Ülkemizde PMI metodolojisinin bilinilirliği ve kullanım yaygınlığı her geçen gün artmakla birlikte, henüz yeterli sayıda firma tarafından tüm yönetim adımlarıyla kullanılamamaktadır. Bunun önemli bir sebebi böyle bir metodoloji uygulamanın firmaya getireceği ek maliyettir. Türkiye'de kar marjı yüksek bazı sektörler hariç, ekonominin büyük bir kısmı düşük kar marjları ile ayakta kalmaya çalışmaktadırlar. Bu durum kurumsallaşmayı ve buna bağlı olarak profesyonelleşmenin önündeki en büyük problemi ifade etmektedir.

Telekomünikasyon firmalarından, Turkcell, Vodafone ve Türk Telekom PMI metodolojisini kullanmaktadırlar. Telekomünikasyon sektörünün yanı sıra, inşaat, lojistik otomotiv ve bilişim sektörlerinde yoğun olarak kullanılmaktadır. Metodolojinin bütün kural ve esaslarını pek çok firma uygulayamasa da, PMI esas prensipleri firmalar tarafından kabul edilmektedir.

Türkiye'de PMI Metodolojisinin öncü uygulayıcısı Türk Telekom firmasıdır. Türk Telekom'un geniş ürün ve hizmet gamı ve sürekli büyüyerek gelişmesi firma yönetiminin, profesyonel bir metodoloji uygulamasını zorunlu kılmıştır. Türk Telekom Proje Yöneticisi ${ }^{6}$ ile yapılmış olan görüşmede, firmanın yıllık 250 adam günlük proje sayısının 250'nin üzerinde olduğunu ve toplamda küçük projelerle birlikte 1000'nin üzerinde projeyi yürüttüğünü ifade etmiştir. Türk Telekom un proje türlerinin de birbirinden çeşitli olması matris organizasyon yapısının kullanılmasını da zorunlu kılmıştır.

\footnotetext{
${ }^{5}$ Proje Yönetimi Bilgi Birikimi Kılavuzu (PMBOK), s:142

${ }^{6}$ Naif Bulut PMP 12.03.2016 tarihli görüşme
} 


\section{SONUÇ}

Gelişen teknoloji ile yapılan yatırımların da büyümesi ve gelişmesine olanak sağlamıştır. Bu durum yapılan yatırımların başarıyla neticelenmesi için sağlıklı ve güvenilir yöntemlerin geliştirilmesini zorunlu kılmıştır. Bunun için, çalışmada esasları ortaya konulan, PMI metodolojisi yaygın olarak kullanılmaktadır. Bu yöntem sayesinde iş süreçlerinin geliştirilmesi ve anlaşılır hale getirilmesini sağlanmaktadır.

İş Kırılım yöntemi sayesinde de en küçük iş paketlerine kadar proje planlanabilmekte ve kontrol altında yürütülmesi sağlanabilmektedir. Yapılan tüm tahminlemelere karşın yine de oluşabilecek risklere karşı da önlem almayı ve risk karşılama planını içermesi açısından yöntem, Proje Yöneticisine büyük imkanlar sağlamaktadır.

Proje Yönetiminin firmaya sağladığı en büyük faydalardan birisi ise yapılan projenin kapanışı esnasında dokümantasyona büyük önem verilmesi ve firmaya 'öğrenilmiş dersler' kazandırmasıdır. Bu sayede firma da yaşanacak her türlü işgücü değişiminde ya da olağandışı bir durum karşısında oluşabilecek aksaklıkların önüne geçilmesi sağlanacaktır.

Türkiye'de uygulanabilirliği hakkında proje yöneticilerinden alınan bilgiye göre, ülkemizde ancak kurumsal firmalar tarafından uygulanabildiğini, küçük firmaların yöntemi tam olarak uygulayamasa da esas prensiplerini ilkesel olarak kurum kültürlerine katmaya çalıştıklarını gözlemlenmektedir.

\section{KAYNAKLAR}

Doğruer, İ. (2007), 'Proje Yönetimi', Açılım Kitap, (1. Baskı b.), İstanbul

Jennifer Greene, A. S. (2009), 'Head First PMP', Oreily Media, Inc.

John M. Nicholas, H. S.' Project Management For Bussiness Engineering and Technology

Project Management İnstitute. (2013), 'Proje Yönetimi Bilgi Birikimi Kılavuzu', Global Standard (çev Karalar, B. (2002),' Türkiye Telekomunikasyon Senaryoları',Yüksek Lisans Tezi, Kocaeli Ünv.

Sönmez, E. (2007, Nisan) 'Neden Proje Yönetimi', Yüksek Lisans Tezi, Mimar Sinan Güzel Sanatlar Ünv.

Project Management İnstitute. (2013), 'Proje Yönetimi Bilgi Birikimi Kılavuzu', Global Standard (çev:PMI TR), Pennslyvania

Güçlü, N. (2003), 'Stratejik Yönetim' Gazi Ünv. Eğitim Fak. Dergisi ,Cilt: 23 , Sayı: 2

Tekir, G. (2012, Ağustos). Proje Ekibinin Yönetilmesi. İstanbul: http://www.gokremtekir.com/index.php/tag/proje-ekibinin-yonetilmesi/, (03.04.2015) 